\title{
Perfil da Exportações, Produtividade e Tamanho das Firmas no Brasil*
}

\author{
Victor Gomes ${ }^{\dagger}$, Roberto Ellery Jr. ${ }^{\ddagger}$
}

Sumário: 1. Introdução; 2. Base de Dados para o Brasil; 3. Mercados por Firmas: Destino das Exportações; 4. Firmas por Mercado; 5. Exportações e Produtividade; 6. Exportações e Tamanho das Firmas; 7. Conclusões.

Palavras-chave: Comércio Internacional; Exportações; Produtividade; Brasil.

Códigos JEL: F14; L25; C31.

A partir de dados da Pesquisa Industrial Anual (PIA), em nível de firma, este trabalho estuda o comportamento de firmas brasileiras que exportam alguma parcela de sua produção. Os principais resultados encontrados são: apenas um pequeno número de empresas realiza exportações; a maioria das firmas exportadoras destina suas exportações a pequeno número de mercados; variações nas exportações brasileiras de um mercado para outro estão mais associadas a variações no número de empresas que exportam para este mercado que ao valor médio das exportações de cada uma; e as firmas exportadoras são maiores e mais produtivas que as atuantes apenas no mercado interno. Cerca de $40 \%$ das firmas exportadoras atuam somente no Mercosul. Estas são menores e menos produtivas que as que exportam para outros mercados.

Using data at firm level this paper studies the behavior of Brazilian firms that exports a share of its production. The main findings are: only a small fraction of firms sell to foreign countries, most exporting firms sell to few markets, variations in Brazilian exports across destinations represents differences in

\footnotetext{
*Este trabalho é parte da pesquisa "Inserção da indústria brasileira: evidências a partir das informações sobre firmas industriais", financiada com recursos do Rede-Ipea, por meio do Projeto BRA 97/013, e foi realizado utilizando os dados da Pesquisa Industrial Anual (PIA), dentro de um convênio de pesquisa entre a Diretoria de Estudos Setoriais (Diset) do Ipea e a Diretoria de Indústria do Instituto Brasileiro de Geografia e Estatística (IBGE) que tornou possível o nosso acesso aos microdados identificados. Entre as pessoas que tornaram este trabalho possível, gostaríamos de agradecer particularmente a João A. De Negri (Ipea) e a Sílvio Salles (IBGE). Gostaríamos também de agradecer as importantes sugestões e os comentários de Paulo F. de Castro. As implicações e as opiniões contidas neste trabalho são de responsabilidade dos autores.

${ }^{\dagger}$ Departamento de Economia, Universidade de Brasília, Campus Darcy Ribeiro, ICC Norte, Asa Norte, Brasília, DF, Brasil. E-mail: victorgomes@unb.br. Homepage: http: //www.victorgomes .com.br.

${ }^{\ddagger}$ Departamento de Economia, Universidade de Brasília, Campus Darcy Ribeiro, ICC Norte, Asa Norte, Brasília, DF, Brasil. E-mail: ellery@unb.br. Homepage: http://www .unb.br/face/eco/rellery.
} 
number of Brazilian firms selling there much more than the amount that each one sells, exporting firms are larger and more productive than non-exporting firms. About $40 \%$ of the exporting firms sell only to the Mercosul, those firms are smaller and less productive than the firms that exports to others countries.

\section{INTRODUÇÃO}

A análise de dados no âmbito da firma para avaliar empiricamente teorias de comércio internacional é um campo em expansão na literatura econômica. Eaton, Kortum e Kramarz (2003 e 2004) apresentam evidências da destinação das exportações para a indústria francesa. Desde que não existam evidências semelhantes para outros países, é razoável questionar em que medida esses fatos são gerais ou tratamse de especificidades da economia francesa. Neste trabalho, são apresentadas evidências para o Brasil que corroboram os fatos estilizados descritos pelos autores supracitados. Embora o Brasil tenha economia menos desenvolvida, geograficamente mal localizada em relação aos grandes fluxos comerciais e com baixo grau de abertura ao comércio internacional, os fatos que relacionam firmas e destinos de exportação são semelhantes aos observados para a França.

Como no caso dos dados franceses, no Brasil é possível obter informações no contexto da firma da manufatura sobre os destinos de exportação e o valor exportado para esses mercados. Também é possível obter dados com várias características da firma, entre estas: receita, pessoal ocupado e custos. Com tais dados é possível saber se produtores individuais exportam, o quanto exportam e para que países destinam seus produtos. Além disso, também obtêm-se informações sobre o produto por trabalhador de cada firma, bem como o seu tamanho em comparação às não-exportadoras. Em suma, o objetivo deste trabalho é descrever detalhadamente as características de firmas brasileiras que realizam exportações.

A base de dados que possibilitou realizar a descrição detalhada dos destinos das exportações brasileiras foi obtida com o cruzamento dos dados da Pesquisa Industrial Anual (PIA) com os dados da Secretária de Comércio Exterior (Secex). Graças a essa base foi possível reproduzir a análise de Eaton, Kortum e Kramarz (op. cit.) para a economia brasileira.

Ao avaliar os principais trabalhos empíricos realizados com dados no âmbito de firmas e plantas, Tybout (2003) mostra três fatos comuns às firmas exportadoras, tais como: i) as firmas que exportam são minoria do total de firmas; ii) essas firmas possuem uma produtividade maior que as que não exportam; e iii) estas vendem no exterior apenas pequena fração de sua produção. Os dados brasileiros confirmam esses três fatos. Além disso, em virtude das características da base de dados construída, foi possível mostrar que a maioria das firmas exportadoras atende apenas a pequeno número de mercados além do Brasil.

Reproduzir os fatos estilizados encontrados para a França e, até onde os dados americanos permitem, para os Estados Unidos é um resultado importante, pois ajuda a construir uma série de fatos estilizados que são comuns a países desenvolvidos e a países em desenvolvimento. A definição de conjunto robusto de fatos estilizados é fundamental na construção e na avaliação de modelos de comércio internacional. Em particular, torna possível estabelecer alguns resultados que qualquer modelo de comércio deve ser capaz de reproduzir.

Vale notar, especialmente, que o fato de que poucas firmas exportam - e, mesmo as que exportam, destinam grande parte de sua produção ao mercado interno - sugerem que as barreiras para exportação desempenham importante papel na definição do comércio internacional. Modelos teóricos incorporam essas barreiras sob a forma de custos do tipo iceberg como em Bernard e et all (2003) ou sob a forma de custos fixos, Melitz (2003). Para esta literatura, os estudos de como as empresas entram em cada mercado são cruciais a fim de determinar qual o modelo adequado a ser perseguido.

A seção 2 apresenta breve descrição da base de dados utilizada. A terceira avalia o destino das exportações brasileiras, cuja ênfase está na proporção de firmas exportadoras e no número de mercados atendidos por firma. A quarta seção explora as relações entre exportações e produtividade; apesar 
de este ser um tema bastante estudado no Brasil e no resto do mundo, o trabalho apresenta novos elementos para discussão ao comparar produtividade e destino das exportações. A quinta seção avalia a relação entre exportações e tamanho da firma e a sexta conclui e apresenta sugestões para novas pesquisas.

\section{BASE DE DADOS PARA O BRASIL}

A pesquisa foi feita a partir dos dados da Pesquisa Industrial Anual (PIA), dos dados da Secretaria de Comércio Exterior (Secex) e de uma terceira base obtida a partir do cruzamento das duas primeiras. Tanto na PIA quanto na Secex as firmas são identificadas pelo Cadastro Nacional de Pessoas Jurídicas (CNPJ), o que quer dizer que firmas pertencentes ao mesmo grupo, com CNPJ diferentes, são tratadas como firmas diferentes ${ }^{1}$. Portanto, as firmas serão tratadas como diferentes entradas no cadastro CNPJ.

O ano escolhido para a análise foi 1999. A escolha foi motivada pela disponibilidade de dados até o momento, futuras pesquisas poderão expandir a análise com dados entre 1996 e 2002. Dessa forma, será possível minimizar o efeito de choques ocorridos durante o ano de análise que possam enviesar o resultado da pesquisa.

A base de dados da PIA não compreende todas as empresas de manufatura instaladas no Brasil. Sua elaboração é feita por meio de questionários respondidos por todas as grandes empresas e por uma amostra aleatória de pequenas empresas. Limitações desse tipo estão presentes em bases de dados de diversos países, até mesmo na dos Estados Unidos, conforme mostram Bernard e Jensen (1995). ${ }^{2}$

Ao descartarem-se as firmas que não responderam as questões relevantes para este trabalho, a base de dados utilizada ficou com 31.398 firmas classificadas em dezesseis setores (excluindo refino de petróleo). Para garantir a comparação com a literatura, os setores escolhidos são os mesmos utilizados nas comparações entre França e Estados Unidos em Eaton et alii (2004), seguindo a Standard Industrial Classification (SIC). Na base de dados elaborada para este trabalho, a classificação dos setores é feita de acordo com a codificação brasileira (Classificação Nacional de Atividades Econômicas - Cnae). Para comparar os dados brasileiros com os da França e os dos Estados Unidos, é aplicado um conversor de classificação da Cnae para o SIC $^{3}$.

No caso da base de dados da Secex, consta o destino de exportações para 54.459 firmas, totalizando 211 destinos de exportação. Portanto, a partir dessa fonte de dados, é possível inferir o valor total exportado Free on Board (FOB) por firma e o país de destino da exportação.

Quando do cruzamento dos dados da Secex, com os da PIA, o número de firmas caiu para 31.398, pois foram excluídas todas as não-manufaturas e as pequenas firmas manufatureiras não presentes na amostra da PIA. Entretanto, para cada uma das firmas restantes é possível determinar o número de mercados em que operam, a quantidade que vendem em cada mercado e qual produto é exportado.

Na Tabela 1, são apresentadas as características básicas dos dados brasileiros, assim como foi feita uma comparação com os dados da França (Eaton et alii, 2004) e dos Estados Unidos (Bernard e Jensen, 1995). Os dados brasileiros se aproximam mais dos americanos, uma explicação para este fato é que ambos excluem uma parte significativa das pequenas plantas ${ }^{4}$.

\footnotetext{
${ }^{1}$ Uma descrição detalhada da PIA pode ser encontrada em Muendler (2003); para uma breve descrição da base de dados da Secex, ver Carneiro (2002).

${ }^{2}$ Para uma descrição da base de dados francesa e uma análise das distorções causadas pela limitação da base de dados americana, ver Eaton et alii (2004).

${ }^{3}$ Esse conversor está disponível on-line na página de Marc A. Muendler, em: <http://econ.ucsd.edu/muendler/html/ brazil.html>.

${ }^{4}$ Assim como na base de dados americana, na base de dados brasileira apenas um terço das pequenas firmas faz parte da amostra a cada ano.
} 


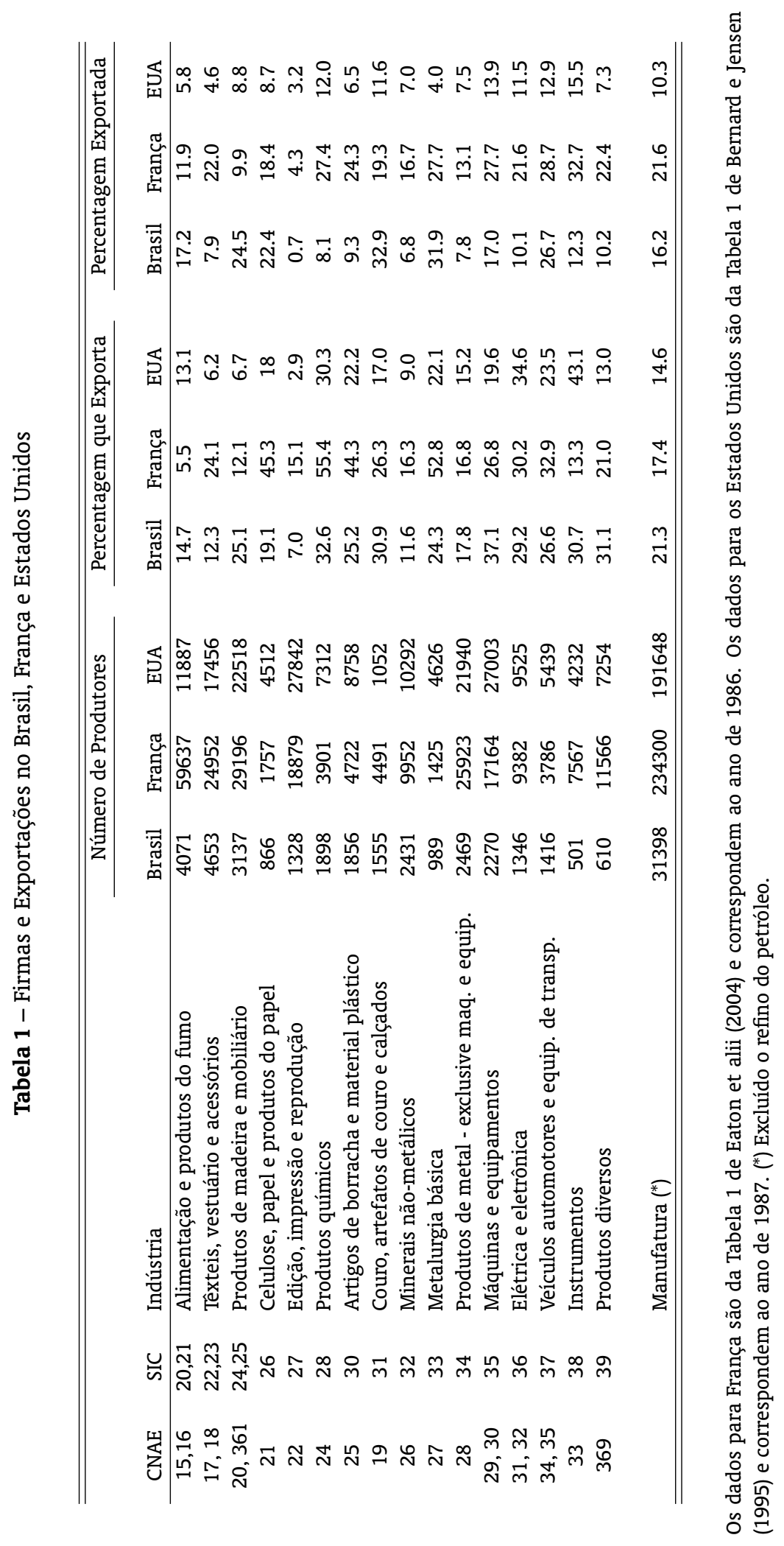




\section{MERCADOS POR FIRMAS: DESTINO DAS EXPORTAÇÕES}

O primeiro resultado importante, e de acordo com o observado em outros países, é que a maior parte das empresas exportadoras atua em poucos mercados. De fato, $48 \%$ das firmas que realizaram exportações em 1999 direcionaram todas as suas exportações para apenas um mercado, enquanto 81\% das firmas exportaram para cinco ou menos mercados.

A Figura 1 mostra a freqüência com que cada firma serviu a diferente número de mercados, excluindo o mercado brasileiro, em 1999. Tal freqüência decresce de forma suave e monótona até que apenas uma firma atenda a um grande número de mercados ${ }^{5}$. Note-se que a relação é claramente decrescente e segue o mesmo padrão encontrado para a França, tal como descrito em Eaton et alii (2004). Outra semelhança notável entre os dados do Brasil e os da França é que no primeiro o número de firmas cai com o aumento de mercados com uma elasticidade de $-2,2$, enquanto no segundo essa elasticidade é de $-2,5^{6}$.

Figura 1 - Entrada de Firmas Brasileiras

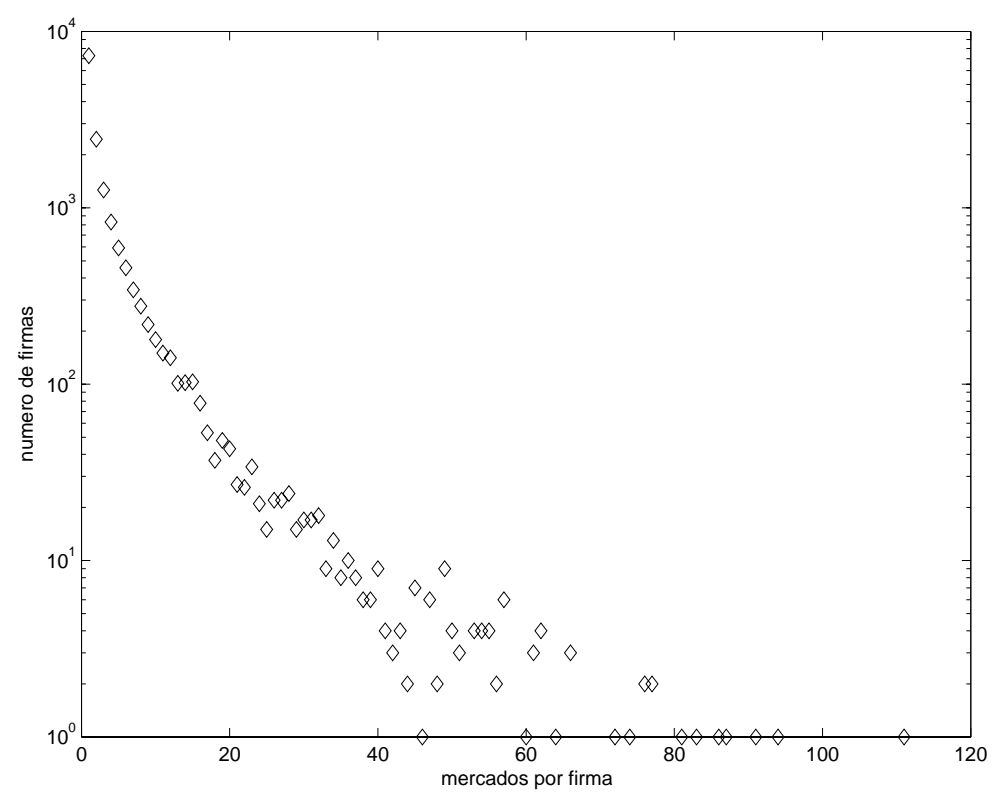

O fato de que poucas firmas realizam exportações - e, mesmo as que exportam, realizam operações em poucos países - corrobora a idéia de que custos de transações desempenham importante papel na decisão das firmas de entrar no comércio internacional. Essa evidência é consistente com as encontradas nos Estados Unidos e na França.

De acordo com a base de dados elaborada para este trabalho, 23,81\% das empresas brasileiras exportam pelos menos $1 \%$ de sua produção para outros mercados. De acordo com o U.S. Census of Manufacturing, no ano de 1992, 21\% das empresas americanas realizaram algum tipo de exportação. Na França, Eaton et alii (2004) reportam que pouco mais de 40 mil das 20 mil firmas constantes na base de

${ }^{5} \mathrm{O}$ número de firmas encontra-se em escala logarítmica, e são considerados apenas mercados externos.

${ }^{6}$ Para obter tal elasticidade, o logaritmo do número de firmas foi regredido contra uma constante e o número de mercados em que as firmas atuam. 
dados utilizada realizaram algum tipo de exportação, o que corresponde a aproximadamente $20 \%$ das firmas?.

A Tabela 1 apresenta o total de firmas em setores selecionados da economia, indica a porcentagem de firmas exportadoras e o quanto de produção estas destinam aos mercados externos ${ }^{8}$. Analisando a tabela 1, é possível perceber que na maioria dos setores o número de firmas brasileiras que realizam exportações é semelhante ao observado nos Estados Unidos e na França. Outro fato importante é que os setores de alta tecnologia, como equipamentos elétricos e eletrônicos, máquinas, computadores e instrumentos, apresentam um alto número de firmas exportadoras.

Para mensurar a intensidade de exportação, a Figura 2 apresenta a distribuição das firmas brasileiras por percentual total da produção exportada. Nessa figura, é possível observar que mais de $60 \%$ das firmas exportam até $10 \%$ de toda a sua produção. Como é o caso dos Estados Unidos, a base de dados para o Brasil não compreende todas as empresas, somente as maiores. Portanto, tal fato pode implicar que o percentual de empresas que exportam sobre o total das empresas brasileiras seja na verdade menor que o sugerido pelos dados. Todavia, a distribuição é parecida com a relatada por Eaton et alii (2003), com o exportador modal vendendo menos de $10 \%$ de sua produção fora do país. No entanto, como na França, existe uma fração substancial de firmas que exportam entre $90 \%$ e $100 \%$ de sua produção.

Figura 2 - Intensidade das Exportações

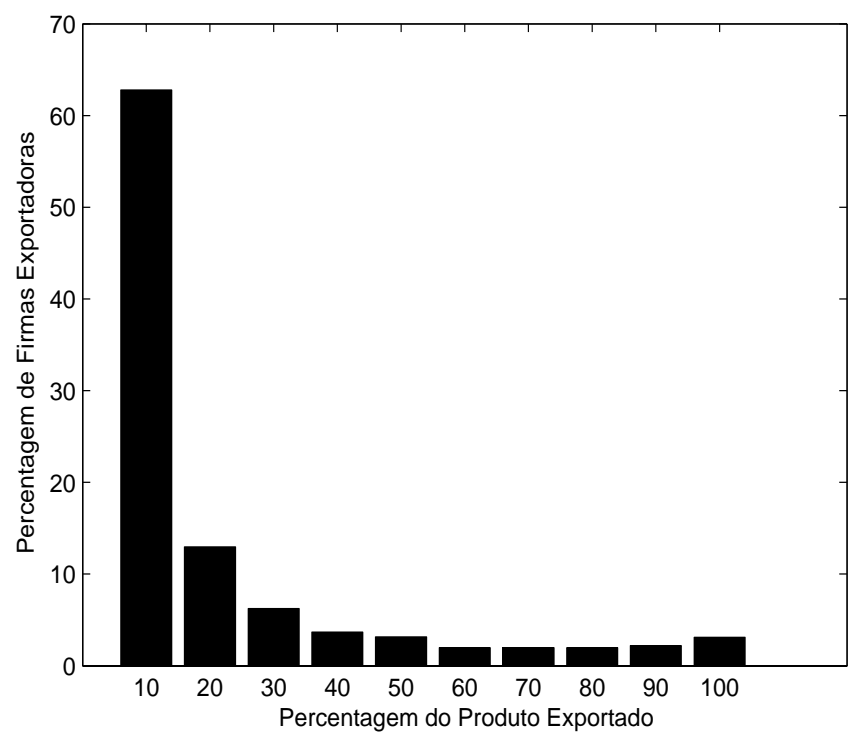

A Tabela 2 mostra a percentagem da produção exportada por firmas em cada setor. Um fato a ser notado é que mais uma vez o padrão de exportações não apresenta grandes diferenças entre os diversos setores. Em doze dos dezesseis setores analisados o número de firmas que exportam menos de $10 \%$ da produção é maior que $50 \%$ do total das firmas exportadoras, apenas em dois setores esse número fica

\footnotetext{
${ }^{7}$ Ao considerar-se que a economia brasileira é relativamente fechada, o resultado de aproximadamente $23 \%$ das firmas realizarem exportações parece acima do esperado. Uma possível explicação para esse resultado é que a PIA considera apenas uma amostra aleatória das pequenas empresas. Isso faz que o papel das grandes empresas, que tendem a exportar mais, seja superestimado nos dados.

${ }^{8}$ A seleção dos setores foi feita de forma que possibilitasse a comparação com os dados para a França e para os Estados Unidos, tais como os apresentados em Eaton et alii (2004).
} 
abaixo de $35 \%$ e em nenhum setor o número de firmas que exportam mais de $10 \%$ é maior que $70 \%$ das firmas do setor. Os dois setores em que mais de $65 \%$ das firmas exportam mais que $10 \%$ da produção são "produtos de madeira e mobiliário" e "couro, artefatos de couro e calçados", explicação para isso pode ser o fato de esses setores serem muito concentrados ou por grandes firmas ou por traders que compram a produção de produtores menores e vendem grande parte da sua produção.

Tabela 2 - Intensidade das Exportações por Setor

\begin{tabular}{clccc}
\hline \hline & & \multicolumn{3}{c}{ Parcela da Produção Exportada } \\
Cnae & Indústria & até $10 \%$ & entre $10 \%$ e $50 \%$ & mais que 50\% \\
\hline 15,16 & Alimentação e produtos do fumo & 46.2 & 27.3 & 26.5 \\
17,18 & Têxteis, vestuário e acessórios & 71.4 & 22.9 & 5.7 \\
20,361 & Produtos de madeira e mobiliário & 30.2 & 25.2 & 44.6 \\
21 & Celulose, papel e produtos do papel & 72.3 & 22.3 & 5.4 \\
22 & Edição, impressão e reprodução & 88.9 & 8.9 & 2.2 \\
24 & Produtos químicos & 66.2 & 27.8 & 6.0 \\
25 & Artigos de borracha e material plástico & 81.6 & 18.4 & 0.0 \\
19 & Couro, artefatos de couro e calçados & 34.0 & 31.3 & 34.7 \\
26 & Minerais não-metálicos & 49.3 & 36.6 & 14.1 \\
27 & Metalurgia básica & 38.3 & 35.6 & 26.1 \\
28 & Produtos de metal - exclusive maq. e equip. & 67.4 & 30.7 & 1.9 \\
29,30 & Máquinas e equipamentos & 62.0 & 33.1 & 4.9 \\
31,32 & Elétrica e eletrônica & 67.4 & 28.9 & 3.7 \\
34,35 & Veículos automotores e equip. de transp. & 57.4 & 35.0 & 7.6 \\
33 & Instrumentos & 61.9 & 36.1 & 2.1 \\
369 & Produtos diversos & 60.8 & 22.3 & 16.9 \\
\hline \hline
\end{tabular}

A semelhança entre o padrão de exportação dos diversos setores pode ser observada de forma mais clara se o gráfico 1 for reproduzido para setores específicos. Seguindo Eaton et alii (2004), o número de mercados atendidos por firmas exportadoras será ilustrado para quatro setores: "alimentação e produtos do fumo" (Cnae 15, 16), "produtos de madeira e mobiliário" (Cnae 20, 361), "produtos químicos" (Cnae 24) e "elétrica e eletrônica" (Cnae 31, 32). Estes setores representam indústrias bastante diferentes entre si e podem servir de ilustração como semelhança entre os diversos setores. A Figura 3 mostra o resultado desse exercício.

Em todos os quatro setores ilustrados na Figura 3 é possível observar a relação decrescente entre o número de mercados atendidos e o número de firmas que atendem a cada mercado ${ }^{9}$. $O$ fato que, em todos os setores, somente uma pequena parte da produção é destinada à exportação não é uma característica somente da economia brasileira. Bernard e Jensen (1995) encontram resultado semelhante quando estudam a economia americana, sendo o mesmo padrão observado por Eaton et alii (2004) para a França.

\section{FIRMAS POR MERCADO}

Uma vez analisado o destino das exportações, a atenção será voltada para o número de firmas que opera em cada mercado. Para isso, será considerada uma amostra de 101 países com dados relativos ao número de firmas brasileiras que exportam para cada país, ao valor das exportações e ao tamanho do mercado de cada país. O tamanho do mercado foi calculado como o valor da absorção total (produção mais importações menos exportações) do país.

\footnotetext{
${ }^{9} \mathrm{Na}$ realidade, esse fenômeno está presente nos dezesseis setores analisados.
} 
Figura 3 - Entrada de Firmas Brasileiras por Setores
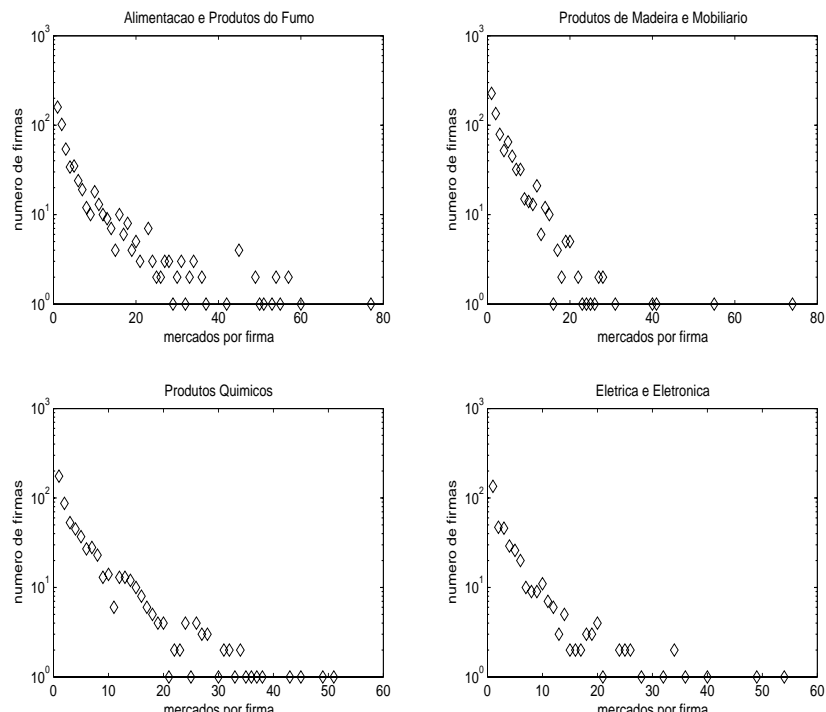

A maneira padrão de modelar o comércio bilateral, que relaciona as exportações do país $i$ para o país $n, X_{n i}$, com o tamanho do mercado do país $n, X_{n}$, e barreiras geográficas entre eles é a equação gravitacional. Esta equação prediz que:

$$
X_{n i}=\kappa \frac{X_{i} X_{n}}{d_{n i}}
$$

onde $d_{n i}$ representa a distância entre os países e $\kappa$ é uma constante dimensional. Neste trabalho, a origem será sempre o Brasil $(i=B)$ e o papel das barreiras geográficas será representado pela participação das exportações brasileiras no mercado estudado, $\lambda_{n B}$; dessa forma, obtém-se:

$$
X_{n B} \equiv \lambda_{n B} X_{n}
$$

Ao utilizar-se a base com os dados da PIA e da Secex, é possível determinar uma segunda identidade, relacionando $X_{n B}$ com o comportamento da firma:

$$
X_{n B}=N_{n B} \tilde{x}_{n B}
$$

onde $N_{n B}$ é o número de firmas brasileiras que vendem para o país $n$ e $\tilde{x}_{n B}$ são as vendas médias por firmas brasileiras no país em questão.

Na Figura 4, é feita a descrição da relação direta entre três elementos dessas duas decomposições[equações (2) e (3)]. No eixo horizontal, está a medida do tamanho de mercado, $X_{n}$. No eixo vertical, está o número de exportadores dividido pela participação brasileira naquele mercado $\left(N_{n B} / \lambda_{n B}\right)$. A evidência que esta figura sugere é que o número de firmas vendendo aumenta sistematicamente com o tamanho do mercado.

Para analisar a relação entre $N_{n B}, \lambda_{n B}$ e $X_{n}$, foi feita uma regressão entre o logaritmo destas três variáveis. A equação resultante foi:

$$
\ln N_{n B}=\underset{(0,304)^{* * *}}{4,666}+\underset{(0,039)^{* * *}}{0,723} \ln \lambda_{n B}+\underset{(0,033)^{* * *}}{0,597} \ln X_{n}
$$


Figura 4 - Entrada e Tamanho do Mercado

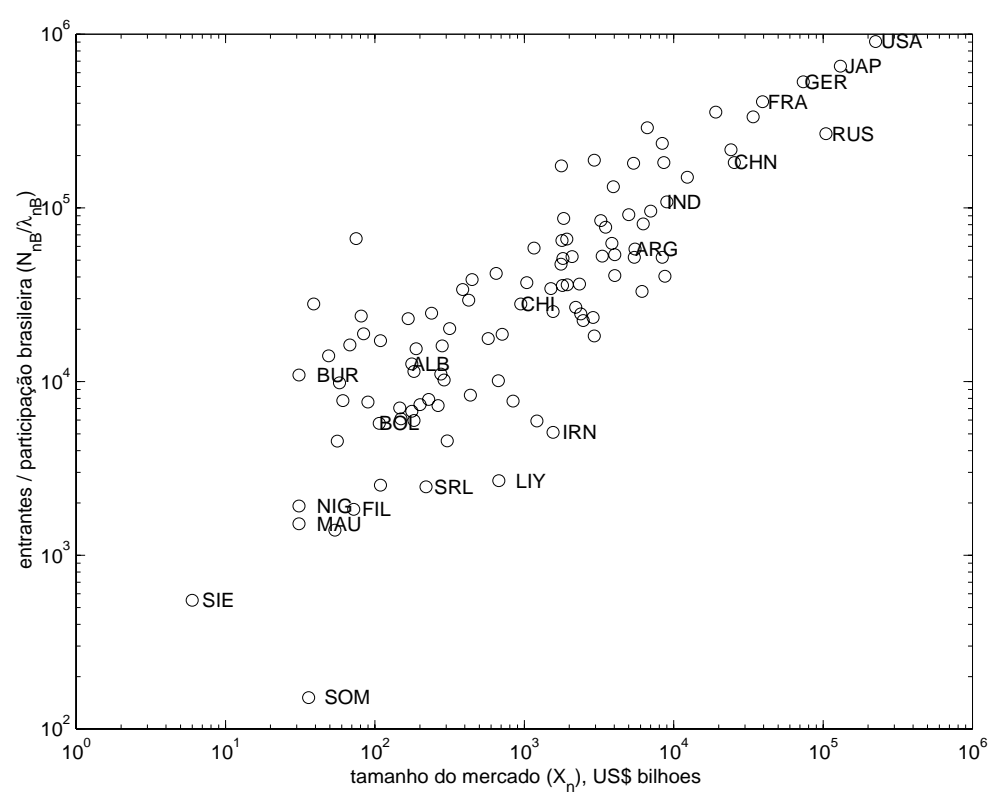

Como pode ser observado pelos desvios-padrão das estimativas todos os parâmetros foram significativos. O poder de explicação da equação foi alto, com $R^{2}=0,87^{10}$.

A implicação desse resultado é que, tendo em vista o tamanho do mercado de um país, um aumento da participação brasileira nesse mercado tipicamente reflete aumento de $72 \%$ nas firmas brasileiras que vendem nesse país e $28 \%$ de aumento nas vendas médias das firmas brasileiras nesse mesmo país. Entretanto, considerando a participação brasileira em um mercado, as vendas para um mercado maior refletem $60 \%$ mais firmas e aumento de $40 \%$ nas vendas por firmas ${ }^{11}$.

Alternativamente, foi feito uso de uma medida de market size mais simples e utilizada na literatura de comércio internacional que é baseada no PIB (Evenett e Keller, 2002). Mesmo utilizando essa medida simples os resultados ficam inalterados. Similarmente a Alvarez e Robert (2004), a absorção de cada país foi medida como PIB de 1999 em dólares americanos (USD) a preços correntes mais importações e menos exportações.

Importações e exportações foram calculadas como a média de 1994-1999 como uma participação do PIB a preços correntes vezes o PIB de 1999. A base de dados utilizada para construir essas medidas foi a International Financial Statistics/International Monetary Fund - IFS/IMF (CD-ROM e on-line database) que é muito acessível para vários pesquisadores ${ }^{12}$. Na equação seguinte, são apresentados os resultados da regressão ilustrada na equação (4) para a medida utilizada de PIB com base em absorção, $G_{n}$.

$$
\ln N_{n B}=\underset{(0,425)^{* * *}}{3,55}+\underset{(0,038)^{* * *}}{0,663} \ln \lambda_{n B}+\underset{(0,028)^{* * *}}{0,559} \ln G_{n}
$$

\footnotetext{
${ }^{10}$ Em todo o restante deste trabalho, ${ }^{* * *}$ significa aceitação em nível de 0,999 e ** a 0,99 de significância.

${ }^{11}$ Para a França, os coeficientes estimados foram 0,875 e 0,617; valores próximos aos encontrados para o Brasil. o $R^{2}$ da regressão com dados franceses foi igual a 0,90 .

${ }^{12}$ Alvarez e Robert (2004) medem a absorção como a média do PIB do país em proporção ao PIB mundial para o período 19942000. Nesta pesquisa, não foi calculada a absorção como média, pois a base de microdados de comércio refere-se apenas a 1999. Todavia, calculou-se o valor médio de importações e de exportações para excluir possíveis influências da volatilidade cambial sobre a medida de absorção.
} 
Para essa regressão, $R^{2}=0,88$. O resultado da regressão mostra a robustez do resultado em relação ao tamanho do mercado. Comparando com o resultado descrito na equação (4), encontra-se um $R^{2}$ ligeiramente superior, 0,87 contra 0,88 .

O fato de essas regressões apresentarem alto poder explicativo, tendo em vista apenas dados do mercado de destino, sugere que características referentes às indústrias podem não ser tão importantes para determinar a entrada de firmas brasileiras em mercados externos. Eaton et alii (2004) realizam testes considerando indicadores de indústria e concluem que estes não são importantes para explicar a entrada de firmas francesas em mercados externos. Seguindo essa idéia, também são consideradas características específicas dos mercados, e, assim como para o caso francês, foi observado que o padrão não difere muito para diferentes indústrias.

Foi realizada uma decomposição em três fatores das exportações do Brasil para $n$ destinos por indústria $s, X_{n B}^{s}$, são eles: i) participação no mercado, $\lambda_{n B}$; ii) absorção $X_{n}$; e iii) o chamado industry bias das exportações brasileiras para o mercado $n, B_{n B}^{s}$; bem como o número de firmas da indústria $s$ que vende no mercado $n$ e as suas vendas médias $\bar{x}_{n B}$, resultando em:

$$
\lambda_{n B} X_{n} B_{n B}^{s} \equiv X_{n B}^{s} \equiv N_{n B}^{s} \bar{x}_{n B}
$$

Para estender a análise anterior, foi feita uma regressão de $N_{n B}^{s}$ em relação a $\lambda_{n B}, X_{n}$ e $B_{n B}^{s}$ para cada indústria $s$. O resultado dessas regressões por mínimos quadrados ordinários está apresentado na Tabela 3. O resultado que emerge é de que os coeficientes são estatisticamente significantes e a sua magnitude varia pouco entre setores, mas não declara a existência de um padrão.

Além disso, apenas os setores de "produtos de madeira e mobiliário" (Cnae 20 e 361), "minerais não-metálicos" (Cnae 26) e "produtos de metal" (Cnae 28) apresentam o $R^{2}$ ligeiramente superior ao encontrado, sem considerar características da indústria. Todavia, como a melhora é de 0,01, em média, não é possível concluir que essa especificação realiza um trabalho melhor que o modelo mais parcimonioso descrito na equação (4). Entretanto, um padrão que pode ser diferente do encontrado, para o caso francês, é o de que o número de mercados de destino não se mantém estável entre diferentes indústrias, cuja média é de 76 mercados, aproximadamente, chegando ao máximo de 90 mercados (máquinas e equipamentos) e ao mínimo de 35 mercados (produtos químicos).

Também foi feita uma pooled regression clustering by industry, com desvios-padrão robustos entre parênteses:

$$
\ln N_{n B}=\underset{(0,183)^{* * *}}{3,514}+\underset{(0,019)^{* * *}}{0,620} \ln \lambda_{n B}+\underset{(0,020)^{* * *}}{0,469} \ln X_{n}+\underset{(0,028)^{* * *}}{0,368} \ln B_{n B}^{s}
$$

o $R^{2}$ para esta equação é 0,776 (para o total de 1.223 observações em dezesseis setores), o que adiciona muito pouco sobre as especificações prévias. 
Tabela 3 - Entrada de Firmas por Indústria

\begin{tabular}{|c|c|c|c|c|c|c|}
\hline Cnae & $\ln \left(\lambda_{n B}\right)$ & $\ln \left(X_{n}\right)$ & $\ln \left(B_{n B}^{s}\right)$ & Número de Mercados & $R^{2}$ & $\mathrm{~F}$ \\
\hline 15,16 & $\begin{array}{c}.594 \\
(.036)^{* * *}\end{array}$ & $\begin{array}{c}.536 \\
(.027)^{* * *}\end{array}$ & $\begin{array}{c}.13 \\
(.047)^{* *}\end{array}$ & 89 & .855 & 166.971 \\
\hline 17,18 & $\begin{array}{c}.692 \\
(.066)^{* * *}\end{array}$ & $\begin{array}{c}.541 \\
(.049)^{* * *}\end{array}$ & $\begin{array}{c}.436 \\
(.047)^{* * *}\end{array}$ & 72 & .822 & 104.502 \\
\hline 20,361 & $\begin{array}{c}.635 \\
(.074)^{* * *}\end{array}$ & $\begin{array}{c}.535 \\
(.059)^{* * *}\end{array}$ & $\begin{array}{c}.473 \\
(.073)^{* * *}\end{array}$ & 70 & .728 & 58.837 \\
\hline 21 & $\begin{array}{c}.7 \\
(.057)^{* * *}\end{array}$ & $\begin{array}{c}.563 \\
(.042)^{* * *}\end{array}$ & $\begin{array}{c}.615 \\
(.045)^{* * *}\end{array}$ & 76 & .873 & 164.992 \\
\hline 22 & $\begin{array}{l}.548 \\
(.031)^{* * *}\end{array}$ & $\begin{array}{c}.305 \\
(.024)^{* * *}\end{array}$ & $\begin{array}{c}.295 \\
(.026)^{* * *}\end{array}$ & 83 & .853 & 152.567 \\
\hline 24 & $\begin{array}{c}.491 \\
(.106)^{* * *}\end{array}$ & $\begin{array}{c}.464 \\
(.066)^{* * *}\end{array}$ & $\begin{array}{c}.281 \\
(.041)^{* * *}\end{array}$ & 35 & .772 & 34.89 \\
\hline 25 & $\begin{array}{c}.705 \\
(.05)^{* * *}\end{array}$ & $\begin{array}{c}.516 \\
(.039)^{* * *}\end{array}$ & $\begin{array}{c}.487 \\
(.053)^{* * *}\end{array}$ & 83 & .841 & 139.201 \\
\hline 19 & $\begin{array}{c}.667 \\
(.052)^{* * *}\end{array}$ & $\begin{array}{c}.446 \\
(.04)^{* * *}\end{array}$ & $\begin{array}{c}.417 \\
(.038)^{* * *}\end{array}$ & 84 & .799 & 106.096 \\
\hline 26 & $\begin{array}{c}.638 \\
(.039)^{* * *}\end{array}$ & $\begin{array}{c}.515 \\
(.03)^{* * *}\end{array}$ & $\begin{array}{c}.577 \\
(.042)^{* * *}\end{array}$ & 82 & .868 & 171.382 \\
\hline 27 & $\begin{array}{c}.691 \\
(.05)^{* * *}\end{array}$ & $\begin{array}{c}.496 \\
(.04)^{* * *}\end{array}$ & $\begin{array}{c}.24 \\
(.048)^{* * *}\end{array}$ & 79 & .821 & 114.46 \\
\hline 28 & $\begin{array}{c}.642 \\
(.044)^{* * *}\end{array}$ & $\begin{array}{c}.467 \\
(.033)^{* * *}\end{array}$ & $\begin{array}{c}.549 \\
(.038)^{* * *}\end{array}$ & 76 & .881 & 177.618 \\
\hline 29,30 & $\begin{array}{l}.684 \\
(.043)^{* * *}\end{array}$ & $\underset{(.036)^{* * *}}{.471}$ & $\begin{array}{c}.503 \\
(.047)^{* * *}\end{array}$ & 90 & .821 & 131.114 \\
\hline 31,32 & $\begin{array}{c}.62 \\
(.058)^{* * *}\end{array}$ & $\underset{(.046)^{* * *}}{.551}$ & $\begin{array}{c}.4 \\
(.052)^{* * *}\end{array}$ & 72 & .807 & 94.878 \\
\hline 34,35 & $\begin{array}{c}.569 \\
(.041)^{* * *}\end{array}$ & $\underset{(.035)^{* * *}}{.404}$ & $\begin{array}{c}.388 \\
(.032)^{* * *}\end{array}$ & 73 & .834 & 115.563 \\
\hline 33 & $\begin{array}{c}.498 \\
(.043)^{* * *}\end{array}$ & $\begin{array}{c}.396 \\
(.034)^{* * *}\end{array}$ & $\begin{array}{c}.318 \\
(.028)^{* * *}\end{array}$ & 82 & .847 & 144.079 \\
\hline 369 & $\begin{array}{c}.497 \\
(.033)^{* * *}\end{array}$ & $\begin{array}{c}.452 \\
(.031)^{* * *}\end{array}$ & $\begin{array}{c}.362 \\
(.028)^{* * *}\end{array}$ & 77 & .858 & 146.537 \\
\hline
\end{tabular}




\section{EXPORTAÇÕES E PRODUTIVIDADE}

Um resultado presente na literatura é que as firmas que participam do comércio internacional tendem a ter maior produtividade que as operantes apenas no mercado interno. Esse resultado pode ser encontrado para dados internacionais em Eaton et alii (2004) e em Bernard e et all (2003). Muendler (2004) e Hay (2001), trabalhando com dados de firmas brasileiras, encontram resultados semelhantes. O mesmo tipo de resultado é encontrado em Ferreira e Rossi (2003), a partir de dados setoriais.

A Tabela 4 mostra a produtividade do trabalho ${ }^{13}$ em cada um dos grupos de firmas definidos na Tabela 2. Em apenas seis setores a produtividade do trabalho cresce à medida que aumenta a quantidade de produto destinado à exportação. Em geral, a Tabela 4 não estabelece uma relação clara entre produtividade do trabalho e total da produção destinada ao mercado externo ${ }^{14}$.

Tabela 4 - Produtividade e Quantidade Exportada

\begin{tabular}{|c|c|c|c|c|}
\hline \multirow[b]{2}{*}{ Cnae } & \multirow[b]{2}{*}{ Indústria } & \multicolumn{3}{|c|}{ Produtividade do Trabalho } \\
\hline & & até $10 \%$ & entre $10 \%$ e $50 \%$ & mais de $50 \%$ \\
\hline 15,16 & Alimentação e produtos do fumo & 29.3 & 40.6 & 33.4 \\
\hline 17,18 & Têxteis, vestuário e acessórios & 16.4 & 16.0 & 19.5 \\
\hline 20,361 & Produtos de madeira e mobiliários & 12.0 & 11.5 & 20.0 \\
\hline 21 & Celulose, papel e produtos do papel & 26.9 & 58.8 & 144.5 \\
\hline 22 & Edição, impressão e reprodução & 48.7 & 37.4 & 72.6 \\
\hline 24 & Produtos químicos. & 64.0 & 82.0 & 53.4 \\
\hline 25 & Artigos de borracha e material plástico & 20.2 & 27.3 & - \\
\hline 19 & Couro, artefatos de couro e calçados & 10.5 & 15.0 & 13.2 \\
\hline 26 & Minerais não-metálicos & 18.1 & 21.0 & 29.9 \\
\hline 27 & Metalurgia básica & 24.5 & 39.8 & 44.7 \\
\hline 28 & Produtos de metal - exclusive maq. e equip. & 21.7 & 30.3 & 54.0 \\
\hline 29,30 & Máquinas e equipamentos & 23.2 & 28.8 & 48.3 \\
\hline 31,32 & Elétrica e eletrônica & 24.7 & 28.3 & 69.7 \\
\hline 34,35 & Veículos automotores e equip. de transp. & 19.6 & 98.8 & 37.7 \\
\hline 33 & Instrumentos & 29.5 & 34.4 & 12.0 \\
\hline 369 & Produtos diversos & 15.7 & 14.7 & 19.9 \\
\hline
\end{tabular}

Para avaliar melhor a questão, foi feita uma regressão entre exportações e produtividade mais uma constante. A regressão foi feita com dados de todas as firmas que declararam o quanto de sua produção é destinado à exportação. 0 resultado foi que, apesar de a produtividade ser significativa em nível de 5\% para explicar as exportações, o poder de explicação foi muito baixo, $R^{2}=0,0008$. Tal resultado reforça a conclusão de o volume de exportação não poder ser explicado pela produtividade do trabalho ${ }^{15}$. De fato, a correlação entre essas duas variáveis é de apenas $2,8 \%$.

Uma outra variável que pode estar relacionada à produtividade do trabalho é o número de mercados em que a firma atua. Eaton et alii (2004) mostram que na França existe uma relação crescente entre essas duas variáveis. A Figura 5 estabelece a relação entre produtividade e número de mercados atendidos para as firmas brasileiras. Nesta figura, firmas que não exportam são consideradas como as que atendem apenas a um mercado.

\footnotetext{
${ }^{13}$ Definida como a razão entre a produção total e o número de empregados da firma.

${ }^{14} \mathrm{Em}$ linha com essa evidência está o fato de que as empresas exportadoras pagam um prêmio salarial 13,6\% maior, conforme descrito por Arbache e Negri (2002).

${ }^{15}$ Note-se que isso não é equivalente a afirmar que a produtividade não ajuda a explicar as exportações.
} 
Figura 5 - Entrada de Firmas Brasileiras e Produtividade

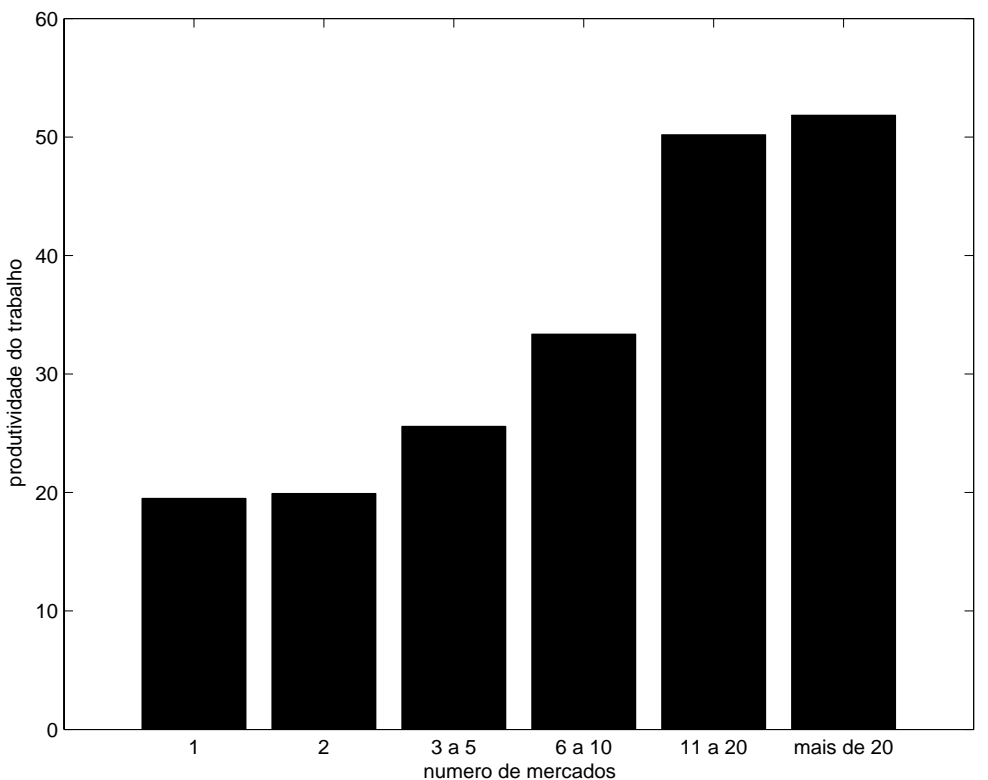

Conforme pode ser observado, a relação entre número de mercados atendidos pela firma e produtividade do trabalho é claramente crescente. A produtividade do trabalho em firmas que atendem a mais de dez mercados é maior que o dobro da produtividade do trabalho em firmas que destinam toda a produção ao mercado interno ou exportam apenas para um país. Em uma regressão do número de firmas atendidas contra uma constante e a produtividade, o coeficiente associado à produtividade foi significativo a menos de $1 \%$; entretanto, o poder explicativo da regressão é muito baixo, o $R^{2}$ foi de aproximadamente 0,009. A correlação entre as duas variáveis é de 9,6\%.

Um outro forte indicativo da relação entre produtividade e exportação é o fato de que a produtividade média das empresas que exportam é aproximadamente $60 \%$ maior que a produtividade média das empresas que não exportam. Nos Estados Unidos, as empresas exportadoras são em média 33\% mais produtivas que as não-exportadoras, enquanto na França essa vantagem é reduzida para 12,5\%. Um dos motivos para tal diferença pode estar relacionado ao tipo de empresas incluídas na amostra.

Uma última análise de interesse compara a produtividade do trabalho das firmas que exportam somente para o Mercosul com a das firmas que exportam para outros países. Nesse caso, os dados mostram que as empresas que exportam apenas para o Mercado Comum do Sul são em média 9,1\% mais produtivas que as atuantes apenas no mercado interno. Quando são consideradas as empresas que exportam para países fora do Mercosul, o diferencial de produtividade é de aproximadamente 67\%, favorável a empresas exportadoras. Ao compararem-se esses dois resultados, conclui-se que as empresas que exportam para países fora desse mercado possuem uma produtividade do trabalho 53\% maior que a das firmas que exportam exclusivamente para o Mercosul.

\section{EXPORTAÇÕES E TAMANHO DAS FIRMAS}

Um último ponto, que é objeto de discussão na literatura sobre o perfil das firmas exportadoras, sendo possível tratar com a base de dados que se dispõe neste trabalho, diz respeito ao tamanho das 
firmas exportadoras. Em geral, observa-se que as firmas exportadoras possuem maior volume de vendas no mercado interno que as firmas não-exportadoras.

No caso dos Estados Unidos, em que a base de dados exclui muitas pequenas empresas, as vendas de uma típica planta exportadora no mercado interno são 5,6 vezes maiores que as vendas de uma planta que não realiza exportações. Na França, em que a base de dados compreende quase todas as plantas em operação, as firmas exportadoras vendem no mercado interno aproximadamente 28 vezes mais que as não-exportadoras.

Para o Brasil, foi usada a amostra obtida com o cruzamento dos dados da PIA e da Secex para analisar o tamanho das firmas exportadoras. Assim como no caso americano, a amostra brasileira não considera um número grande de pequenas empresas. 0 resultado encontrado foi que a típica firma exportadora é 6,1 vezes maior que a típica firma que não exporta. $O$ fato de esse número estar mais próximo do americano que do francês pode ser explicado pelas características dos dados utilizados em cada país.

Além do fato de as firmas exportadoras serem maiores no mercado interno que as não-exportadoras, Eaton et alii (2004) mostram que as firmas que detêm maior parcela do mercado doméstico tendem a exportar para maior número de países. A Figura 6 ilustra essa relação para o Brasil.

Figura 6 - Entrada de Firmas Brasileiras e Tamanho da Firma

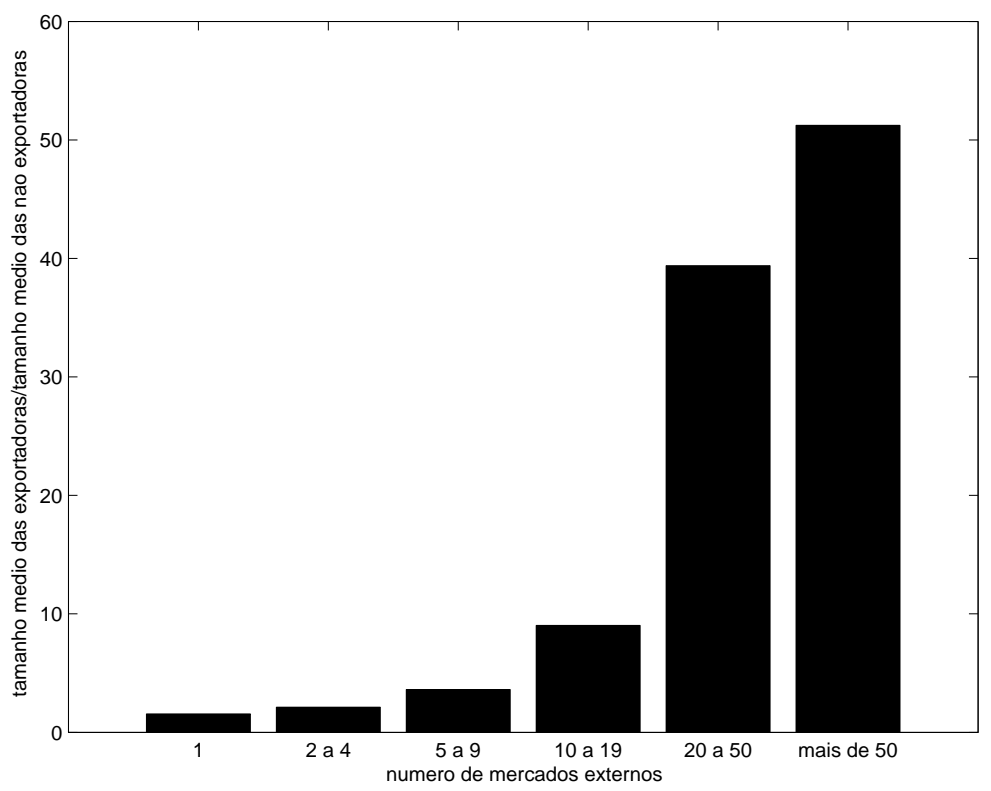

Ao observar-se a Figura 6, é possível notar a relação crescente entre o tamanho da firma e o número de mercados atendidos pela firma. Enquanto as firmas que exportam para dez ou menos mercados são em média 2,38 vezes maiores que as firmas que não exportam, as firmas que atuam em mais de cinqüenta mercados chegam a ser mais de 50 vezes maiores que as firmas não-exportadoras.

0 tipo de comparação descrito anteriormente pode ser feito em relação às empresas que exportam apenas para o Mercosul e às que exportam para outros países. Nesse caso, é possível mostrar que as firmas que exportam somente para o Mercosul são em média $13 \%$ maiores que as não-exportadoras, enquanto as firmas que exportam para outros países, além do Mercosul, são 3,3 vezes maiores que as não-exportadoras. 


\section{CONCLUSÕES}

A análise dos dados da PIA e da Secex revela que o comportamento das firmas brasileiras em relação à decisão de exportar é semelhante ao de outros países, especificamente dos Estados Unidos e da França. Uma conclusão imediata desse resultado é que o fato de o Brasil ser um país em desenvolvimento não parece ser particularmente relevante para determinar o perfil das exportações.

Dessa forma, o trabalho contribui para a construção de um conjunto de fatos estilizados que possam ser utilizados na avaliação de modelos de comércio. Em particular, a evidência empírica apresentada mostra que um modelo de comércio internacional para ser aplicado ao Brasil deve ser capaz de explicar que:

1. O número de empresas exportadoras é pequeno em relação ao total de empresas no mercado; além disso, o número de firmas que exportam para vários mercados decresce com o número de mercados. Esse padrão não depende do setor em que a firma atua.

2. O aumento da participação brasileira em mercados externos está muito mais associado ao aumento do número de firmas que exportam para este mercado do que ao aumento das vendas médias das firmas exportadoras.

3. Firmas exportadoras possuem produtividade do trabalho maior que firmas que não exportam; ademais, firmas que exportam para muitos mercados são mais produtivas que firmas que exportam para poucos mercados.

4. Firmas exportadoras são maiores que firmas não-exportadoras; quanto maior a firma, a mais mercados ela atende.

Uma vez que esses fatos são comuns a outros países, torna-se razoável argumentar que qualquer modelo de comércio internacional deve ser capaz de responder pelos quatro fatos citados anteriormente.

Quando a análise volta-se ao Mercosul, o primeiro ponto a chamar atenção é o fato de que $40 \%$ das empresas brasileiras que exportam atendem apenas aos países participantes do bloco. A produtividade do trabalho dessas empresas é 9,1\% maior que a das empresas que não exportam, entretanto é de aproximadamente $66 \%$ da produtividade do trabalho de empresas que exportam para fora do Mercosul.

Tal resultado pode ser interpretado como uma evidência de que o Mercosul cumpre o papel de facilitar as exportações de firmas brasileiras para a Argentina, o Paraguai e o Uruguai. Isso é verdade, pois seria mais fácil exportar para tais países, uma vez que esse tipo de exportação não exige alta produtividade da firma. Uma objeção para tal conclusão seria argumentar que a proximidade geográfica facilitaria o acesso a esses mercados independentemente da formação do bloco regional. Para avaliar essa hipótese, seria necessário elaborar um conjunto de dados semelhante ao utilizado neste trabalho, porém cobrindo um período anterior à criação do Mercosul.

A evidência de o Mercosul viabilizar a exportação de firmas com menor produtividade do trabalho pode servir como desestímulo ao aumento da produtividade. Esse aspecto deve ser considerado nas discussões sobre o grau de comprometimento do Brasil com a formação do Mercosul, em detrimento a políticas de comércio que englobem um maior número de países.

O fato de as firmas que exportam apenas para o Mercosul serem maiores que as firmas não-exportadoras e menores que as firmas que exportam para outros países, associado à evidência de que as firmas que exportam para mais de vinte países são muito maiores que as firmas que exportam para menos de dez países, sugere que a existência de custos fixos associados a exportações possui importante papel na decisão de exportar. Dessa forma, políticas que visem facilitar o acesso de firmas brasileiras a mercados externos podem gerar o crescimento significativo das exportações brasileiras. Outro resultado importante para a elaboração de políticas públicas é que políticas que visem ao aumento na produtividade das firmas podem ter efeito positivo sobre as exportações.

RBE Rio de Janeiro $\quad$ v. 61 n. 1 / p. 33-48 Jan-Mar 2007 
Futuras pesquisas devem expandir a amostra de firma, incorporando outros anos para os quais os dados da PIA e da Secex estão disponíveis. A criação desse painel pode gerar um resultado mais robusto na medida em que reduz o efeito de choque específico ao ano da pesquisa.

\section{Referências Bibliográficas}

Alvarez, F. \& Robert, E. L. J. (2004). General equilibrium analysis of the eaton-korum model of international trade. manuscrito.

Arbache, J. S. \& Negri, J. A. D. (2002). Diferenciais de salários interindustrias no brasil. texto para discussão 918, Instituto de Pesquisa Econômica Aplicada (IPEA).

Bernard, A. B. \& et all (2003). Plants and productivity in international trade. American Economic Review, 93(4):1268-1290. available at http://ideas.repec.org/a/aea/aecrev/ v93y2003i4p1268-1290.html.

Bernard, A. B. \& Jensen, J. B. (1995). Exports, jobs, and wages in u.s. manufacturing: 1976 - 1987. Brooking Papers on Economic Ativity: Microeconomics, pages 67-119.

Carneiro, F. G. (2002). Destino das exportações e canais de comercialização das maiores empresas exportadoras brasileiras. texto para discussão 917, Instituto de Pesquisa Econômica Aplicada (IPEA).

Eaton, J., Kortum, S., \& Kramarz, F. (2003). An anatomy of international trade: evidence from french firms. manuscrito.

Eaton, J., Kortum, S., \& Kramarz, F. (2004). Dissecting trade: Firms, industries, and export destinations. American Economic Review, 94(2):150-154. available at http://ideas.repec.org/a/aea/ aecrev/v94y2004i2p150-154.html.

Evenett, S. J. \& Keller, W. (2002). On theories explaining the success of the gravity equation. Journal of Political Economy, 110(2):281-316. available at http://ideas.repec.org/a/ucp/jpolec/ v110y2002i2p281-316.html.

Ferreira, P. C. \& Rossi, J. L. (2003). New evidence from brazil on trade liberalization and productivity growth. International Economic Review, 44(4):1383-1405. available at http://ideas.repec.org/ a/ier/iecrev/v44y2003i4p1383-1405.html.

Hay, D. A. (2001). The post-1990 brazilian trade liberalisation and the performance of large manufacturing firms: Productivity, market share and profits. Economic Journal, 111(473):620-41. available at http://ideas.repec.org/a/ecj/econjl/v111y2001i473p620-41.html.

Melitz, M. J. (2003). The impact of trade on intra-industry reallocations and aggregate industry productivity. Econometrica, 71(6):1695-1725. available at http://ideas.repec.org/a/ecm/emetrp/ v71y2003i6p1695-1725.html.

Muendler, M.-A. (2003). The database pesquisa industrial anual 1986 - 2001: a detective's report. Technical report, Instituto Brasileiro de Geografia e Estatística.

Muendler, M.-A. (2004). Trade, technology and productvity: a study of brazilian manufacturers, 1996 1998. manuscrito.

Tybout, J. R. (2003). Plant and firms level evidence on 'new' trade theories. In Handbook of International Trade. Oxford: Basil Blackwell. 